\title{
Ultrasound-guided methotrexate injection for De Quervain disease of the wrist: what lies beyond the horizon?
}

This article was published in the following Dove Press journal:

Journal of Pain Research

26 September 2017

Number of times this article has been viewed

\begin{abstract}
Abdallah El-Sayed Allam', Doaa Shawky Al-Ashkar', Ahmed A Negm², Basma

Aly Eltawab ${ }^{3}$, Wei-Ting $\mathrm{Wu}^{4}$, Ke-Vin Chang ${ }^{4}$

'Department of Physical Medicine, Rheumatology and Rehabilitation, Tanta University Hospitals, Faculty of Medicine, Tanta University, Tanta, Egypt; ${ }^{2}$ Department of Physical Medicine, Rheumatology and Rehabilitation, Faculty of Medicine, Al-Azhar University, Cairo, Egypt; ${ }^{3}$ Department of Radiology, Tanta University Hospitals, Tanta, Egypt; ${ }^{4}$ Department of Physical Medicine and Rehabilitation, National Taiwan University Hospital, Bei-Hu Branch, Taipei, Taiwan
\end{abstract}

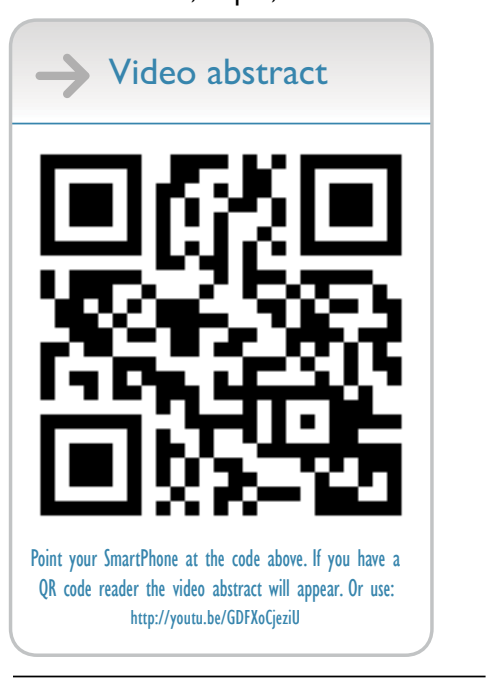

Correspondence: Ke-Vin Chang Department of Physical Medicine and Rehabilitation, National Taiwan University Hospital, Bei-Hu Branch, National Taiwan University College of Medicine, 87 Neijiang Street, Wanhua, Taipei 10845, Taiwan

Email: pattap@pchome.com.tw

\begin{abstract}
De Quervain disease (DQVD) is one of the most common causes of lateral wrist pain and can lead to significant disability. The current case involves a right-handed, middle-aged, female patient with severe lateral wrist pain due to DQVD. Her pain was not responsive to oral non-steroidal anti-inflammatory drugs, rehabilitation, and repeated corticosteroid injections. Because she refused surgical intervention, we performed ultrasound-guided methotrexate injections (four times). After the injections, dramatic pain relief, functional improvement, and reduction of the thickness of the retinaculum and tendons in the first dorsal extensor compartment of the wrist were noted. This case report highlights the potential usefulness of ultrasound-guided methotrexate injection for recalcitrant DQVD of the wrist.
\end{abstract}

Keywords: hand, pain, sonography, rehabilitation

\section{Introduction}

De Quervain disease (DQVD) was first described by Fritz De Quervain in 1895 as a stenosing tenosynovitis of the abductor pollicis longus and extensor pollicis brevis tendons within the first dorsal extensor compartment of the wrist. ${ }^{1}$ It is a common cause of wrist pain and disability involving the dominant hand among middle-aged women. ${ }^{2}$ Most patients respond well to non-operative management, which includes immobilization of the thumb, non-steroidal anti-inflammatory drugs, physiotherapy, and local corticosteroid injection. ${ }^{3}$ Ultrasound-guided injection for DQVD helps in precisely targeting the involved tendons and reduces collateral damage to the neurovascular structures ${ }^{4-6}$ The present case report aimed to demonstrate the potential usefulness of methotrexate in a patient with recalcitrant DQVD.

\section{Consent for publication}

We obtained written permission from the patient to publish this case report and the accompanying images.

\section{Case description}

The patient was a 38-year-old right-handed female farmer with hypothyroidism, who had been taking $100 \mathrm{mg}$ L-thyroxine sodium (Eltroxin) once daily since March 2013 and she denied having systematic disease like hypertension, diabetes mellitus, rheumatoid arthritis, and other rheumatic diseases. In February 2014, she complained of right lateral wrist pain and was prescribed an oral non-steroidal anti-inflammatory drug under the diagnosis of De Quervain tenosynovitis. Because of incomplete pain relief after conserva- 
tive treatment the patient was given corticosteroid injections by an orthopedic surgeon (three times) through palpation guidance combined with immobilization with a thumb spica cast, from May 2014, and her visual analog scale (VAS) was 1/10 after the last injection in August 2015. The patient did not receive ultrasound examination at that clinic due to inaccessibility of the machine. Her symptoms recurred in January 2016 with a VAS of 10/10. Surgical intervention was recommended to the patient, however, she refused surgery. She was referred to the Department of Physical Medicine at Tanta University Hospital. In our clinic, the physical findings revealed swelling and tenderness over the radial styloid with a positive Finkelstein's test. The first metacarpal phalangeal joint appeared normal in range of motion and was not painful during palpation. Percussion of the radial styloid did not provoke the Tinel sign. We arranged a musculoskeletal ultrasound scan on February 10, 2016, which revealed marked thickening of the extensor retinaculum and swelling of the tendons inside the first dorsal wrist extensor compartment. There was no increase in power Doppler signals. There were no fibrous septa dividing the first extensor compartment (Figure $1 \mathrm{~A}-\mathrm{C}$ ). After obtaining written consent, we injected $0.5 \mathrm{~mL}$ methotrexate $(6.25 \mathrm{mg})$ with $0.5 \mathrm{~mL}$ mepivacaine $(15 \mathrm{mg}$ ), four times starting from February 15,2016 , with an interval of 10 days between each injection under ultrasound guidance by using the in-plane approach, to target the short axis of the tendon sheath (Figure 2A). No adverse event was reported after the injections, and the patient reported gradual reduction of pain. Her VAS declined to 8/10,
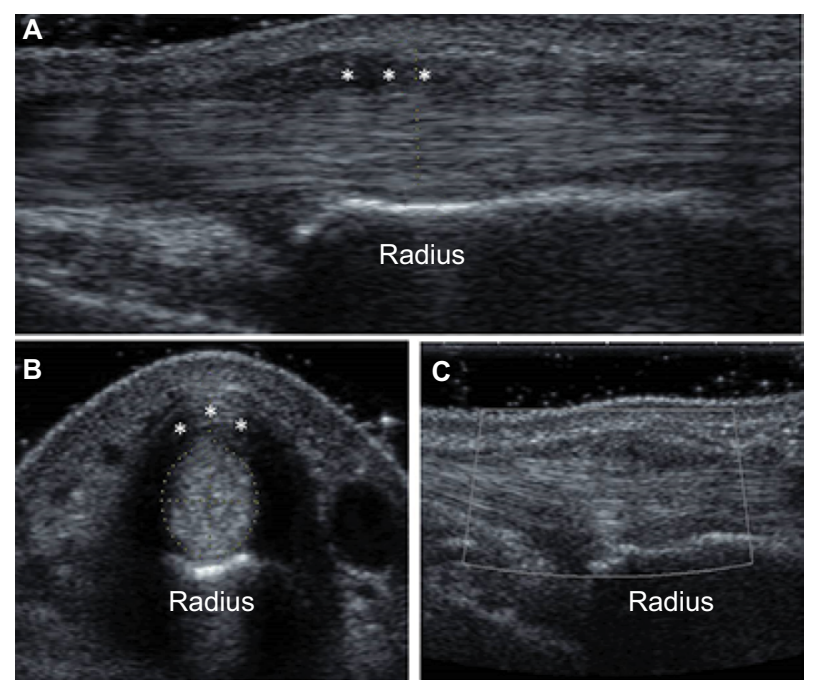

Figure I Ultrasound findings before methotrexate injection.

Notes: (A) Longitudinal scan of the tendons in the first dorsal extensor compartment of the wrist. (B) Transverse scan of the tendons in the first dorsal extensor compartment of the wrist. *The retinaculum. (C) Power Doppler examination of the tendons of the first dorsal extensor compartment of the wrist revealed no activity.
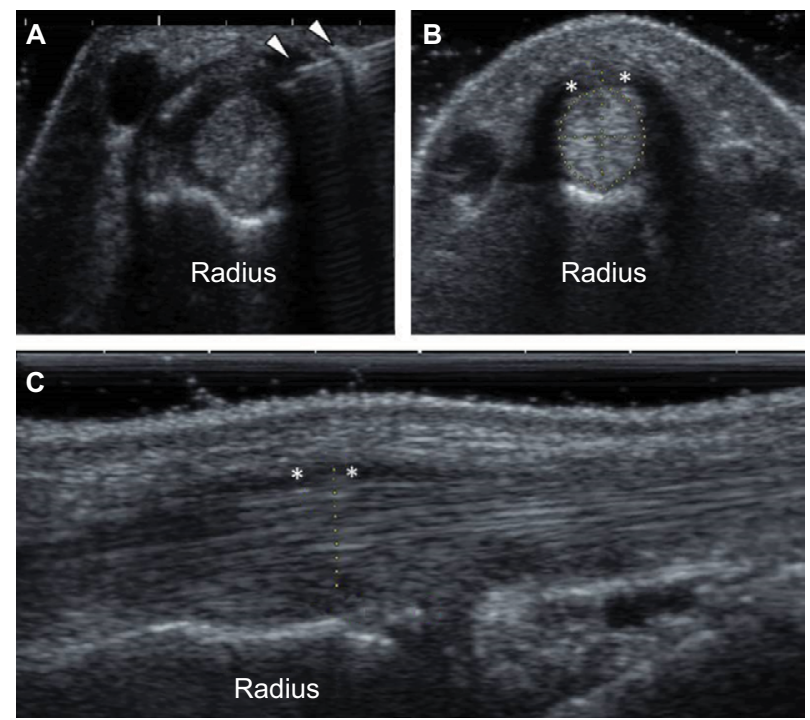

Figure 2 Ultrasound findings after methotrexate injection.

Notes: (A) Ultrasound-guided injection by using an in-plane short axis approach. Arrowheads indicate the needle. (B) Transverse scan of the tendons in the first dorsal extensor compartment of the wrist. *The retinaculum. (C) Longitudinal scan of tendons in the first dorsal extensor compartment of the wrist.

$7 / 10,4 / 10$, and $1 / 10$ after each injection, respectively. By November 2016, the patient reported being pain free (VAS $0 / 10$ ), and no more injections were administered. A follow-up ultrasound scan revealed a marked reduction in the size of the thickened retinaculum (from 3 to $1.2 \mathrm{~mm}$ ) and swollen tendons (from 5.5 to $5.1 \mathrm{~mm}$ ) in comparison with images taken before methotrexate injections (Figure $2 \mathrm{~B}$ and $\mathrm{C}$ ).

\section{Discussion}

DQVD affects $0.5 \%$ of working men and $1.3 \%$ of working women. ${ }^{7}$ Pregnancy, early motherhood, and postmenopausal status predispose women to the development of DQVD. ${ }^{8}$ Frequently, DQVD involves the dominant hand; however, involvement of the non-dominant hand is also encountered in clinical practice..$^{9,10}$ The etiology is still unclear, and the risk factors include certain anatomic variations such as multiple tendons inside the first dorsal extensor compartment, presence of a fibrous septum, and mechanical overloading. The net result is inflammation of the tendon sheath, or thickening of the tendon and retinaculum. Microtears of the abductor pollicis longus and extensor pollicis brevis tendons may progress to complete rupture and complicate the treatment course. The underlying causes also influence the response to conservative treatments such as non-steroidal anti-inflammatory drugs, rehabilitation, and local steroid injection. ${ }^{8,11-13}$ Current literature suggests that corticosteroid injection is indicated in severe cases at the first visit and has a higher rate of remission than immobilization alone. ${ }^{14}$ 
Musculoskeletal ultrasound plays an important role in the detection of the anatomic variations of the first extensor compartment, including septa, tendon slips, and osseous ridges. ${ }^{15}$ It can reveal many pathological findings such as synovial hypertrophy, peritendinous hypervascularity, thickening of the retinaculum and tendon, and intratendinous microtears. ${ }^{8,9,16}$ Additionally, ultrasound-guided injection prevents intratendinous injection and reduces the risk of subsequent tear, ${ }^{17}$ precisely introduces the injectate to the affected region in case of an intracompartmental septum, ${ }^{18}$ and prevents the superficial radial nerve from the injury. ${ }^{19} \mathrm{In}$ this case, ultrasound imaging clearly demonstrated thickening of the retinaculum, which might be the main factor leading to recurrence after overuse of the wrist.

Methotrexate, a disease modifying antirheumatic drug, is widely used in the treatment of rheumatoid arthritis. A key feature of intra-articular pathology of rheumatoid arthritis is hypertrophic synovium, ${ }^{20}$ which is commonly seen in recalcitrant stenosing tenosynovitis. ${ }^{8}$ The medication also can be safely administered for knee synovitis without preexisting rheumatic conditions. ${ }^{21}$ Therefore, the rationale of using methotrexate to treat DQVD is based on its potential effect to antagonize hypertrophic synovium. Methotrexate has anti-inflammatory and immunomodulatory effects owing to an elevated level of adenosine,$^{20}$ which decreases pain by suppressing the production of substance $\mathrm{P}^{22}$ prostaglandins, cytokines, and collagenases. ${ }^{23}$ Moreover, methotrexate has antifibrotic effects through the inhibition of fibroblasts. ${ }^{24}$ Injection of methotrexate has been widely used in the treatment of rheumatoid arthritis, psoriatic arthritis, and juvenile idiopathic arthritis and has shown promising effectiveness. ${ }^{25,26}$ Ultrasound-guided methotrexate injection can be safely administered at least every 7 days up to 8 times for the treatment of synovitis. ${ }^{27}$ Therefore, in this case, methotrexate not only resolved the inflammation inside the first dorsal extensor compartment of the wrist but also reduced hypertrophy of the retinaculum by reducing fibroblast activity. This dual effect is rarely seen with corticosteroid injection, which mainly contributes to reduction of inflammation at the injection site. However, the use of methotrexate may be associated with gastrointestinal upset, bone marrow toxicity, and hepatotoxicity. It is contraindicated in cases of hepatic and renal impairment; thus, the function of both the liver and kidney should be assessed before starting methotrexate therapy. ${ }^{23}$ Ultrasound guidance can prevent unwanted spreading of the methotrexate, to reduce the risk of tissue necrosis and demyelinating neuropathy of the superficial radial nerve. The main limitation of the study is its case number $(n=1)$ and lack of a control. The beneficial effect of methotrexate could result from hydrodissection of the tendon. Therefore, a future randomized controlled trial should be conducted to investigate the true effectiveness of intrasheath methotrexate injection for DQVD.

\section{Conclusion}

Ultrasound-guided methotrexate injection could be a safe and effective method in the management of recalcitrant DQVD. Further large-scale studies are needed to compare its effectiveness with corticosteroid injection or surgical intervention.

\section{Acknowledgment}

The current research project was supported by the National Taiwan University Hospital, Bei-Hu Branch and the Ministry of Science and Technology (104-2314-B-002-022-MY2 and 106-2314-B-002-180-MY3).

\section{Author contributions}

All authors contributed toward data analysis, drafting and critically revising the paper, gave final approval of the version to be published, and agree to be accountable for all aspects of the work.

\section{Disclosure}

The authors report no conflicts of interest in this work.

\section{References}

1. Lee HJ, Kim PT, Aminata IW, Hong HP, Yoon JP, Jeon IH. Surgical release of the first extensor compartment for refractory de Quervain's tenosynovitis: surgical findings and functional evaluation using DASH scores. Clin Orthop Surg. 2014;6(4):405-409.

2. Wolf JM, Sturdivant RX, Owens BD. Incidence of de Quervain's tenosynovitis in a young, active population. J Hand Surg Am. 2009;34(1): $112-115$.

3. Menendez ME, Thornton E, Kent S, Kalajian T, Ring D. A prospective randomized clinical trial of prescription of full-time versus as-desired splint wear for de Quervain tendinopathy. Int Orthop. 2015;39(8):1563-1569.

4. McDermott JD, Ilyas AM, Nazarian LN, et al. Ultrasound-guided Injections for de Quervain's Tenosynovitis. Clin Orthop Relat Res. 2012;470(7):1925-1931.

5. Volpe A, Pavoni M, Marchetta A, et al. Ultrasound differentiation of two types of de Quervain's disease: the role of retinaculum. Ann Rheum Dis. 2010;69(5):938-939.

6. Chan ES, Cronstein BN. Molecular action of methotrexate in inflammatory diseases. Arthritis Res. 2002;4(4):266-273.

7. Dębek A, Czyrny Z, Nowicki P. Sonography of pathological changes in the hand. J Ultrason. 2014;14(56):74-88.

8. Vuillemin V, Guerini H, Bard H, Morvan G. Stenosing tenosynovitis. J Ultrasound. 2012;15(1):20-28.

9. De Maeseneer M, Marcelis S, Jager T, Girard C, Gest T, Jamadar D. Spectrum of normal and pathologic findings in the region of the first extensor compartment of the wrist: sonographic findings and correlations with dissections. J Ultrasound Med. 2009;28(6):779-786.

10. Lutsky K, Kim N, Medina J, Maltenfort M, Beredjiklian PK. Hand dominance and common hand conditions. Orthopedics. 2016;39(3):e444-e448. 
11. Fu SC, Rolf C, Cheuk YC, Lui PP, Chan KM. Deciphering the pathogenesis of tendinopathy: a three-stages process. Sports Med Arthrosc Rehabil Ther Technol. 2010;2:30.

12. Stahl S, Vida D, Meisner C, Stahl AS, Schaller HE, Held M. Work related etiology of de Quervain's tenosynovitis: a case-control study with prospectively collected data. BMC Musculoskelet Disord. 2015;16:126.

13. Kuo YL, Hsu CC, Kuo LC, et al. Inflammation is present in de Quervain Disease-correlation study between biochemical and histopathological evaluation. Ann Plast Surg. 2015;74(supp1 2):S146-S151.

14. Stephens MB, Beutler AI, O’Connor FG. Musculoskeletal injections: a review of the evidence. Am Fam Physician. 2008;78(8):971-976.

15. Rousset P, Vuillemin-Bodaghi V, Laredo JD, Parlier-Cuau C. Anatomic variations in the first extensor compartment of the wrist: accuracy of US. Radiology. 2010;257(2):427-433.

16. Chiavaras MM, Jacobson JA, Yablon CM, Brigido MK, Girish G. Pitfalls in wrist and hand ultrasound. AJR Am J Roentgenol. 2014;203(3):531-540.

17. Speed CA. Fortnightly review: corticosteroid injections in tendon lesions. BMJ. 2001;323(7309):382-386.

18. Chang KV, Hung CY, Özçakar L. Ultrasound imaging for precise diagnosis and injection of isolated extensor pollicis brevis tenosynovitis: it is not always a simple de Quervain disease. Am J Phys Med Rehabil. 2015;94(3):255.

19. Cheong IY, Rhyu IJ, Kim KH, et al. Anatomical basis for injection around first dorsal compartment of the wrist: a Fresh Cadaveric Study. Pain Physician. 2016;19:E893-E900.
20. Cutolo M, Sulli A, Pizzorni C, et al. Anti-inflammatory mechanisms of methotrexate in rheumatoid arthritis. Ann Rheum Dis. 2001;60:729-735.

21. Hasso N, Maddison PJ, Breslin A. Intra-articular methotrexate in knee synovitis. Rheumatology (Oxford). 2004;43(6):779-782.

22. Baig JA, Iqbal MP, Rehman R, Qureshi AA, Ahmed M. Anti-inflammatory role of methotrexate in adjuvant arthritis: effect on substance $\mathrm{p}$ and calcitonin gene-related peptide in thymus and spleen. J Coll Physicians Surg Pak. 2007; 17(8):490-494.

23. Omoigui S, Fadare A, Ogbechie C. Relief and resolution of fibromyalgia symptoms with low dose methotrexate - the origin of pain is inflammation and the inflammatory response. Rheumatology. 2014; 4:129.

24. Szabò H, Fiorino G, Spinelli A, et al. Review article: anti-fibrotic agents for the treatment of Crohn's disease-lessons learnt from other diseases. Aliment Pharmacol Ther. 2010;31(2):189-201.

25. Iagnocco A, Cerioni A, Coari G, Ossandon A, Masciangelo R, Valesini G. Intra-articular methotrexate in the treatment of rheumatoid arthritis and psoriatic arthritis: a clinical and sonographic study. Clin Rheumatol. 2006;25(2):159-163.

26. Behzad H, Javadian Y. Treatment of refractory arthritis with intraarticular methotrexate, a report of four cases. Indian J Rheumatol. 2015;10:171-172.

27. Mortada M, Solyman A. THU0133 Intra-articular methotrexate: Clinical and power doppler ultrasonography study of synovitis in medium seized joints of rheumatoid arthritis patients. Ann Rheum Dis. 2013;71:200.
Journal of Pain Research

\section{Publish your work in this journal}

The Journal of Pain Research is an international, peer reviewed, open access, online journal that welcomes laboratory and clinical findings in the fields of pain research and the prevention and management of pain. Original research, reviews, symposium reports, hypothesis formation and commentaries are all considered for publication.

\section{Dovepress}

The manuscript management system is completely online and includes a very quick and fair peer-review system, which is all easy to use. Visit http://www.dovepress.com/testimonials.php to read real quotes from published authors. 